\title{
Health-related quality of life of patients with asthma: a cross-sectional study in Semnan, Islamic Republic of Iran
}

Naim S. Kia ${ }^{1}$, Farhad Malek ${ }^{2}$, Elaheh Ghods ${ }^{1}$ and Mona Fathi ${ }^{3}$

\begin{tabular}{|c|}
\hline 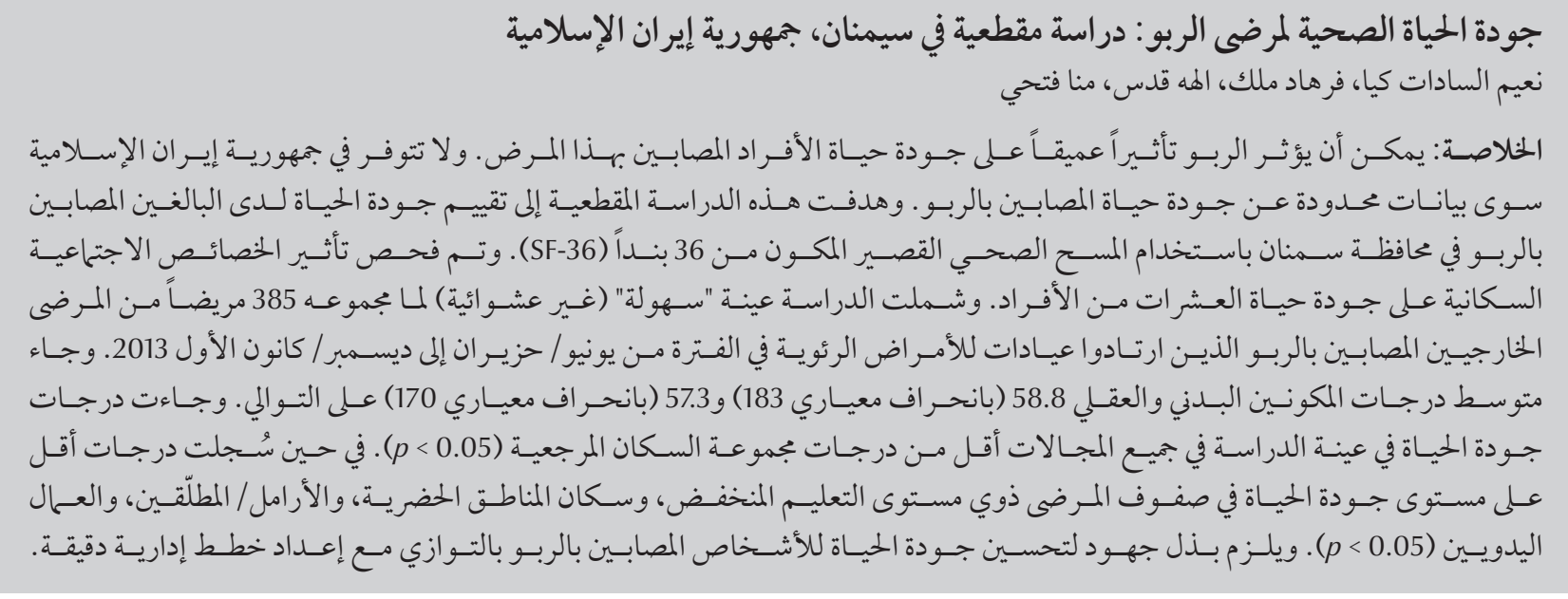 \\
\hline
\end{tabular}

ABSTRACT Asthma can profoundly affect the quality of life of individuals with the disease. There are limited data on the quality of life of people with asthma in the Islamic Republic of Iran. This cross-sectional study aimed to evaluate quality of life in adults with asthma in Semnan using the 36-item short form health survey (SF-36). The effect of sociodemographic characteristics on quality of life scores was examined. The study included a convenience sample of 385 outpatients with asthma attending a pulmonary clinic from June to December 2013. The mean physical and mental component scores were 58.8 (SD 18.3) and 57.3 (SD 17.0) respectively. The study sample had lower quality of life scores in all the fields than the reference population $(P<0.05)$. Patients with lower education, urban residents, widowed/divorced patients and manual workers had lower quality of life scores $(P<0.05)$. Efforts are needed to improve the quality of life of people with asthma in parallel with precise management plans.

Qualité de vie liée à la santé de patients asthmatiques : étude transversale à Semnan, République islamique d'Iran

RÉSUMÉ L'asthme peut affecter gravement la qualité de vie des personnes qui en souffrent. Les données sur la qualité de vie des personnes vivant avec l'asthme en République islamique d'Iran sont en nombre limité. La présente étude transversale avait pour objectif d'évaluer la qualité de vie des adultes asthmatiques à Semnan sur la base du SF-36, un questionnaire court d'enquête sur la santé comprenant 36 items. L'effet des caractéristiques socio-démographiques sur les scores de la qualité de vie a été examiné. L'étude incluait un échantillon de commodité de 385 patients externes souffrant d'asthme et s'étant rendus dans une clinique spécialisée pour les maladies pulmonaires entre juin et décembre 2013. Les scores moyens des composantes physiques et mentales étaient de 58,8 (ET 18,3) et 57,3 (ET 17,0) respectivement. L'échantillon de l'étude affichait des scores inférieurs pour la qualité de vie dans tous les domaines par rapport à la population de référence $(p<0,05)$. Les patients ayant un niveau d'instruction moindre, les habitants urbains, les patients veufs/divorcés et les travailleurs manuels obtenaient des scores de la qualité de vie plus faibles $(p<0,05)$. Des efforts sont requis pour améliorer la qualité de vie des patients asthmatiques parallèlement à la mise en place de plans précis pour leur prise en charge.

'Department of Community Medicine, Social Determinants of Health Research Center, Faculty of Medicine, Semnan University of Medical Sciences, Semnan, Islamic Republic of Iran (Correspondence to: ElahehGhods: ghodsemla@yahoo.com; elaheghods@semums.ac.ir).2Department of Internal Medicine, Faculty of Medicine, Semnan University of Medical Sciences, Semnan, Islamic Republic of Iran. ${ }^{3}$ Faculty of Medicine, Semnan University of Medical Sciences, Semnan, Islamic Republic of Iran.

Received: 07/10/15; accepted: 20/11/16 


\section{Introduction}

According to the latest report of the Global Initiative for Asthma (GINA), about 334 million people in the world have asthma (1). Although the data about adults over 45 years are not precise, the number of asthma patients has increased considerably in the past 30 years. It is estimated that by 2025,100 million people will have asthma globally, an approximate $50 \%$ increase in every decade $(1,2)$.

The estimated global prevalence of asthma is $4.5 \%$ (3). In Asia, which is the most changing population in the world, less than $5 \%$ of adults are diagnosed with clinical asthma (4) and in the Eastern Mediterranean region this is between $2.74 \%$ and $3.12 \%$ (3). Based on the latest report, the prevalence of asthma in the Islamic Republic of Iran was higher than the global rate of disease and is estimated between $5.1 \%$ and $7.5 \%(5,6)$

The global burden of asthma is high because of its high prevalence, the prolonged duration of the disease and because it affects a considerable proportion of the population of working age.

Asthma affects various aspects oflife, including lifestyle, well-being, health, personal satisfaction, occupation and education $(7,8)$. Quality of life (QoL) is a subjective and multidimensional index of well-being from a patient's point of view. It is defined as physical, emotional, social, material well-being and development, activity functional ability (9). It has become more important with increased life expectancy and changes in the pattern of disease as a result of advancements in medical sciences in order to evaluate cost-utility and cost-effectiveness of health care programs (4).

There are different instruments for assessment of QoL in adults (9). However, none of them can evaluate the effect of asthma on all of the key dimensions of QoL and none is able to provide a core assessment. Even the most disease-specific tools such as the
Asthma Quality of Life Questionnaire discriminate poorly between subscales $(8,10)$. The Short Form Health Survey (SF-36) is the most common validated, rapid, self-rated assessment tool for adult disease, despite lower inter-class correlation and minor responsive index compared with disease-specific scales such as the Asthma Quality of Life Questionnaire. It has allowed comparison of QoL in different disease states and can be useful to evaluate patientreported outcome measures (11-13).

All of these instruments have shown lower QoL scores in people with asthma compared with those without the disease $(7,10)$. Several factors could affect QoL of people with asthma, such as age, socioeconomic status, education level and marital status. These factors could modify classification, diagnosis and treatment of asthma (14). Despite the importance of assessing QoL in chronic respiratory diseases such as asthma, there has been limited research on QoL in people with asthma in the Islamic Republic of Iran. This study therefore aimed to evaluate the QoL in adults with asthma and the sociodemographic characteristics associated with it.

\section{Methods}

\section{Study setting and sample}

This was cross-sectional study of adult asthma patients referred to the pulmonary clinic of the University of Semnan from June to December 2013.

A convenience sample was selected of 385 asthma patients aged 18 years or older. All patients were approached during their routine follow-up care in the pulmonary clinic and asked for their participation in the study. All those approached agreed to participate.

Asthma was diagnosed by a pulmonary subspecialist based on chronic persistent inflammation with acute episodic exacerbations and reduced lung function confirmed by spirometry, forced expiratory volume per second (FEV1) before and 15 min after administration of $400 \mathrm{mg}$ (2-3 puffs) of albuterol or equivalent (8). Asthma patients who were affected by other serious chronic physical or psychological diseases, such as cancer and major depression, based on self-report, were excluded from the study.

\section{Ethical considerations}

The study was approved by the Semnan UniversityEthics Committee. Informed consent was obtained from all the participants before data collection.

\section{Data collection}

Demographic data, including age, marital status, occupation and education were collected by interview at the pulmonary clinic. The Persian version of SF-36 questionnaire was used to evaluate QoL $(11,15)$.

SF-36 has 8 domains and 36 questions and includes a physical component score (PCS) and mental component score (MCS), selected from the medical outcomes study in 1992 (16). PCS has 4 scales: Physical Functioning, Physical Role, Bodily Pain and General Health. MCS has 4 scales: Vitality, Social Functioning, Emotional Role and Mental Health (17). Participants are scored individually in each area $(0=$ worst to $100=$ best $)$; the lower the score the lower the QoL.

The reliability and internal consistency of this tool has determined (18). It can be used in different countries and for different diseases or even for comparison between groups with a disease and healthy groups (17).Validation of the SF-36 for measurement of QoL in people with asthma has been done and its suitability for this group established (19). The Farsi version of the SF-36 questionnaire has been validated (20) and used in different studies in our country (20-23).

\section{Statistical analysis}

The data were entered into SPSS, version 16. The QoL scores of the participants are presented as medians and ranges or as means and standard deviations 
(SD) according to sociodemographic characteristics. Analysis was done by one-way ANOVA, one-sample t-test and independent $\mathrm{t}$-test when necessary.

\section{Results}

A total of 385 patients with asthma [177 (45.5\%) females; 208 (53.5\%) males] were enrolled in the study. The mean age of the patients was 48.7 (SD $15.2)$ years. Of all the participants, 263 (68.6\%) were married, 46 (11.9\%) were widowed/divorced and 76 (19.5\%) were single. Older patients with had lower QoL in all domains except for Mental Health $(P<0.001)$.

Mean physical functioning and mental health scores of the patients with asthma were 58.8 (SD 18.3) and 57.3 (SD 17.0) respectively. The PCS score of the study group was significantly better than the MCS score $(P<0.001)$. Table 1 shows the mean scores of all PCS and MCS scales in the patients with asthma and the general population.

The association between the patient demographic and socioeconomic characteristics and their QoL is shown in Table 2. The participants with lower education levels had significantly lower scores in all domains except for Physical Role and Emotional Role. Higher income was associated with higher scores in all the domains. Among employed patients, manual workers had lower QoL in all domains. Compared with urban residents, those living in rural areas had higher QoL scores in the areas of Physical Functioning, Bodily Pain, General Health and Emotional Role. Patients who had shorter duration of the disease also had higher QoL scores in all domains, except for Emotional Role. Single patients had significantly higher scores in all the areas of PCS but the association was significant only for Vitality.

Table 3 shows the correlation between the different variables based on the results obtained from the SF 36 questionnaire. The lowest PCS and MCS were among those in lowest income category ( $P=0.001$ for both $)$ and manual workers ( $P=0.001$ for both). Patients with a disease duration of more than 15 years $(P=0.001)$, urban residence $(P=0.001)$ and widowed or divorced $(P=0.001)$ had significantly lower physical scores. Higher physical score were found in patients with a master's degree or higher $(P<0.001)$. There were no differences in MCS and PCS by sex.

\section{Discussion}

The assessment of disease outcomes based on QoL score is an important concern, particularly for chronic noncommunicable diseases.

Our study showed found lower QoL scores in asthma patients than in the general population, which concurs with the results of other studies in this field which used different scales $(10,11)$.

The results of our study showed that the mean PCS and MCS of individuals with asthma were 58.8 (SD 18.3) and 57.3 (SD 17.0) respectively. As expected, the mean score of the asthma group was significantly lower than that of the general Iranian adult population (15). Patients with asthma have also been reported to have lower General Health but higher Emotional Role scores compared with pregnant women experiencing domestic violence (20), lower Physical Functioning, Physical Role, General Health and Mental Health scores than adolescents with premenstrual disorder (21), lower scores in Emotional Role, Physical Role and Physical Functioning compared with patients with diabetes (22), and lower scores in all subdomains except General Health than patients with thalassemia major (23).

Based on results of a large epidemiological study, mean PCS and MCS score in asthma patients was 45.6 and 48.1 respectively (11). In another study in France, the General Health QoL score was 65-88 for mild to moderate asthma and 63-78 for severe asthma

\begin{tabular}{|c|c|c|c|}
\hline \multirow[t]{2}{*}{ Domain } & Asthma patients & Reference population (15) & $P$-value \\
\hline & Mean $(S D)^{a}$ & Mean $(\mathrm{SD})^{\mathrm{a}}$ & \\
\hline Physical functioning & $58.4(27.6)$ & $85.3(20.8)$ & $<0.001$ \\
\hline Physical role & $49.5(33.1)^{\mathrm{b}}$ & $70.0(38.0)$ & $<0.001$ \\
\hline Bodily pain & $72.1(21.2)$ & $79.4(25.1)$ & $<0.001$ \\
\hline General health & $55.2(16.7)$ & $67.5(20.4)$ & $<0.001$ \\
\hline Vitality & $55.9(17.5)$ & $65.8(17.3)$ & $<0.001$ \\
\hline Social functioning & $66.6(20.3)$ & $76.0(24.4)$ & $<0.001$ \\
\hline Emotional role & $49.3(36.1)^{b}$ & $65.6(41.4)$ & $<0.001$ \\
\hline Mental health & $57.3(17.7)$ & $67.0(18.0)$ & $<0.001$ \\
\hline
\end{tabular}

${ }^{a}$ Analysis by one-sample t-test

${ }^{b}$ Median $(I Q R)$.

$S D=$ standard deviation 


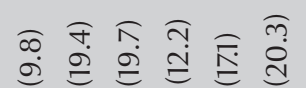

$\pi$ ก के 8000 ถิ

ช่

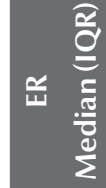

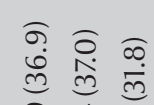

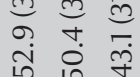

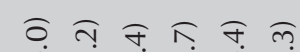

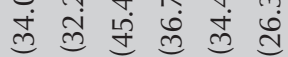

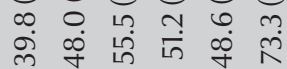

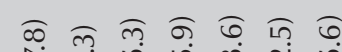

लें में

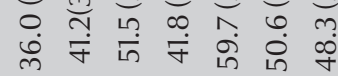

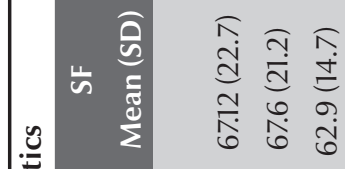

$\frac{2}{30}$

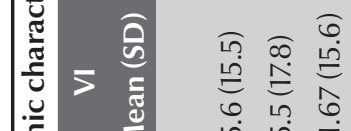

สิ สุ

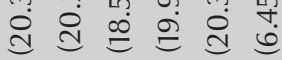

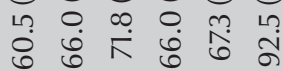

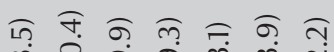

过

藏

लุ.

तิ $\widehat{\overbrace{}}$

₹ ?

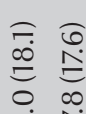

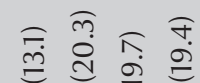

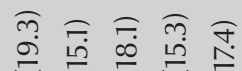

ก $\infty \cong \sigma$

ถึ่

다. (n)

กิ

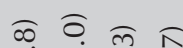

สิ

एलं

话

స్ల

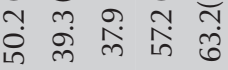

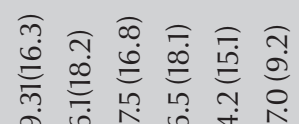

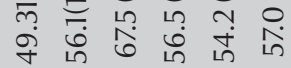

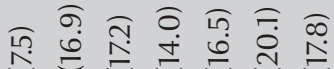

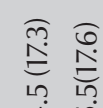

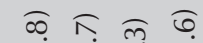

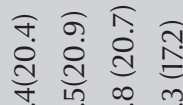
䓎

อิ Е पु

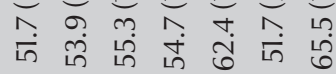

$=\widehat{0} \widehat{\bar{m}} \widehat{\bar{\sigma}} \widehat{\infty}$

అु

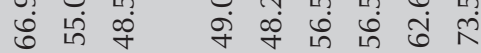

o กั กั

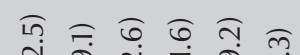
ปู के

बำ ป

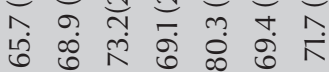

6 m 0 n $\infty$ में ำ ㄴำ

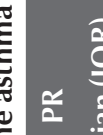

สิธ

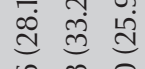
$\begin{array}{lll}0 & \infty & 0 \\ & \dot{+} & \dot{+}\end{array}$

สิธ ํ.

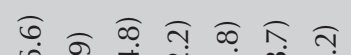

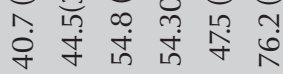

瑳

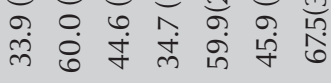

6

莺

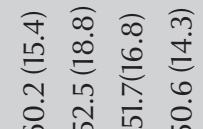

守令

站

గ. $\widehat{x}$

के

ปิ่

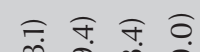

ขูป

मे

ฮே.

巳

$=\infty \pi$

लुల్ర

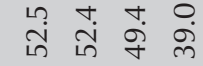

倠

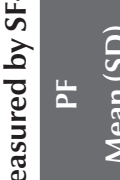

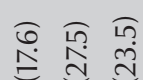

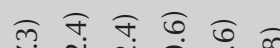

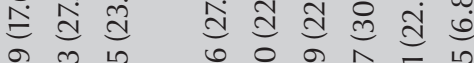

in 00 क

0 o 0 .

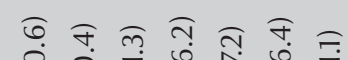

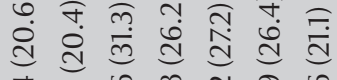

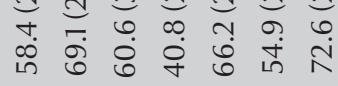

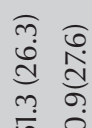

o

షูป⿺辶寸 L

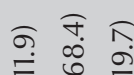

के

ปูก

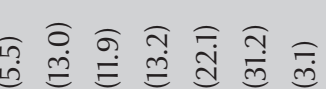
o.

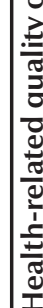

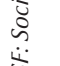




\begin{tabular}{|c|c|c|c|c|}
\hline \multirow[t]{2}{*}{ Variable } & PCS & \multirow[t]{2}{*}{$P$-level } & MCS & \multirow[t]{2}{*}{$P$-level } \\
\hline & Mean (SD) & & Mean (SD) & \\
\hline \multicolumn{5}{|l|}{ Marital status } \\
\hline Single & 73.9 (13.8) & \multirow{3}{*}{$0.001^{\mathrm{a}}$} & $61.2(14.0)$ & \multirow{3}{*}{$0.07^{\mathrm{a}}$} \\
\hline Married & $59.9(18.1)$ & & $57.6(18.5)$ & \\
\hline Widowed, divorced & $45.9(12.8)$ & & $54.0(12.6)$ & \\
\hline \multicolumn{5}{|l|}{ Education level } \\
\hline Illiterate & $50.5(18.9)$ & \multirow{6}{*}{$0.001^{\mathrm{a}}$} & $49.9(16.4)$ & \multirow{6}{*}{$0.1^{\mathrm{a}}$} \\
\hline$<9$. years & $52.7(15.7)$ & & $57.7(15.1)$ & \\
\hline $9-$ & $62.4(17.1)$ & & $65.8(18.3)$ & \\
\hline Diploma & $60.7(19.2)$ & & $56.9(17.5)$ & \\
\hline University, BSc & $63.8(15.0)$ & & $57.6(16.4)$ & \\
\hline University, $\geq \mathrm{MSc}$ & $83.8(5.7)$ & & $69.5(7.4)$ & \\
\hline \multicolumn{5}{|l|}{ Occupation } \\
\hline Manual worker & $51.4(19.6)$ & \multirow{7}{*}{$0.001^{\mathrm{a}}$} & $50.4(13.1)$ & \multirow{7}{*}{$0.001^{\mathrm{a}}$} \\
\hline Government employee & $64.6(15.1)$ & & $51.8(16.9)$ & \\
\hline Office worker & $55.3(17.9)$ & & $57.0(19.1)$ & \\
\hline Retired & $49.2(16.4)$ & & $54.5(13.8)$ & \\
\hline Self-employed & $65.8(18.0)$ & & $63.8(17.9)$ & \\
\hline House-wife & $54.3(16.4)$ & & $56.2(18.0)$ & \\
\hline other & $74.4(15.5)$ & & $62.6(8.9)$ & \\
\hline \multicolumn{5}{|l|}{ Residence } \\
\hline Urban & $52.9(18.3)$ & \multirow{2}{*}{$0.001^{\mathrm{b}}$} & $54.9(15.9)$ & \multirow{2}{*}{$0.1^{\mathrm{a}}$} \\
\hline Rural & $60.9(18.0)$ & & $58.1(17.4)$ & \\
\hline \multicolumn{5}{|l|}{ Duration of disease (years) } \\
\hline$<5$ & $61.8(17.9)$ & \multirow{4}{*}{$0.001^{\mathrm{a}}$} & $56.5(13.6)$ & \multirow{4}{*}{$0.65^{\mathrm{a}}$} \\
\hline $5-$ & $58.7(18.9)$ & & $58.5(17.5)$ & \\
\hline $10-$ & $59.9(17.9)$ & & $56.6(21.4)$ & \\
\hline$>15$ & $50.1(17.5)$ & & $59.1(18.3)$ & \\
\hline \multicolumn{5}{|l|}{ Income ( $\times 10000$ rials $)$} \\
\hline$<500$ & $55.5(17.4)$ & \multirow{5}{*}{$0.001^{\mathrm{a}}$} & $56.7(16.8)$ & \multirow{5}{*}{$0.001^{\mathrm{a}}$} \\
\hline $500-$ & $62.3(21.9)$ & & $57.6(15.6)$ & \\
\hline $1000-$ & $50.3(14.4)$ & & $51.6(14.6)$ & \\
\hline $1500-$ & $65.8(16.9)$ & & $59.1(17.1)$ & \\
\hline$>2000$ & $70.2(17.2)$ & & $66.4(18.5)$ & \\
\hline \multicolumn{5}{|l|}{ Sex } \\
\hline Male & $57.9(18.5)$ & \multirow{2}{*}{$0.32^{\mathrm{b}}$} & $56.2(18.3)$ & \multirow{2}{*}{$0.18^{b}$} \\
\hline Female & $59.8(18.2)$ & & $58.8(15.4)$ & \\
\hline
\end{tabular}

${ }^{a}$ One-way ANOVA; ${ }^{b}$ Independent t-test.

$S D=$ standard deviation .

(14). Comparing different assessment scales for health-related QoL (SF 36, Asthma Quality of Life Questionnaire and modified shortened Living With Asthma Questionnaire), there was only modest correlation between physical score SF 36 and asthma control over time, in spite of the strength of SF 36 in detecting burden of illness overall and measuring non-specific situation that affect quality of life $(12,15)$. On the other hand, recent research has shown a good sensitivity of SF 36 for treatment efficacy of different disease states (24).
Therefore, QoL assessment with SF 36 could be applicable for this case and even better for comparative studies.

In our study, the highest score was observed in Physical Pain domain and the lowest score in Emotional Role functioning. Due to the type of 
disease pathogenesis, it is expected that asthma results in little or no pain and moderately good social functioning, however dyspnea and wheezing lead to disability and subsequent negative feelings $(12,20)$. Reid et al. reported the lowest score in Vitality (12) which is in contrast to our results.

Our findings showed lower MSC scores compared with the PSC scores, which is in agreement with the results of previous research (20). Although the mental score of SF 36 concentrates more on depression, anxiety is a main factor in asthma attacks (19). It has been reported that there is a cyclical interaction between respiratory symptoms in asthma and the likelihood of mood disorders, which limits physical and emotional functioning in people with asthma $(25,26)$. Mental health has a strong role in the control of asthma (27). Mood disorders decrease the efficacy of treatment and increase the recurrence of acute attacks, which further reduces QoL (28).

In our study, PCS was significantly higher in rural residents with asthma. The higher incidence of asthma in recent years could be explained by changes in environmental and geographical factors (29). Actually the prevalence and morbidity of asthma is lower in rural areas than urban areas $(29,30)$. This difference could be explained by differences in a number of environmental and lifestyle factors between urban and rural areas: for example air pollution, diet, energy sources, biomass fuel, farming, livestock and occupational exposures, dust mites, vehicle emissions, respiratory infection and a westernized lifestyle $(12,29)$. The conflicting reports of higher morbidity from asthma in rural areas could be explained by a higher proportion of those aged 55 years or older (i.e. longer duration of disease too), low income, lack of health insurance coverage and college education in suburban and rural areas (29-32).

Lower PCS and MCS scores in our study were associated with lower education, lower level of job and lower income. A significant correlation was observed between higher socioeconomic status and better QoL in individuals with asthma (29). Moreira et al. in a retrospective cohort study with a large sample of 40000 found a lower incidence of asthma in the subgroup with higher income (31). Several studies are in agreement with the results of our study of a lower QoL among those with lower socioeconomic status $(2,29,30)$. A higher level of education, a stable job and health insurance also improve the QoL of individuals with asthma (30,31).

These relationships could be interpreted in different ways. Patients with higher education and those with higher incomes are more likely to schedule regular follow-up visits and show better adherence to treatments. Lower education increases the likelihood of underestimating the significance of control and treatment plans (32).

Similar to the results of our study, a European study found significantly lower PCS scores in manual workers (11). Manual workers are more likely to be exposed to allergens than office workers (3). However, different job classifications between countries make the interpretation of contradictory results difficult $(11,30,31)$.

We found some evidence of an inverse relationship between duration of disease and QoL. Rajanandh et al. found a similar relationship in patients who had had asthma for more than 5 years (33). Another study also showed lower PCS score in older patients, who had likely had the disease for a long period (11).
In our study, widowed and divorced individuals had lower QoL scores than single and married individuals. Previous studies suggest widows have a lower QoL than the general population, mainly because of their lower incomes (34). Psychological disorders are also more common in this group of people (35). The better QoL for younger patients with asthma could be explained by a short duration of the disease and fewer complications.

There was no significant sex difference in QoL scores in our study. In contrast, the results of several studies indicate that female patients with asthma are likely to have a greater perception of dyspnea, report a poorer control and have a poorer QoL compared with males and they recommended sexspecific management protocols (11).

A limitation of our study was the lack of response by some participants on some of the variables evaluated, such as monthly income and severity of asthma. In addition, we did not have access to validated Farsi version of the Asthma Quality of Life Questionnaire to use in parallel with the SF-36 health survey, which would have strengthened our assessment and allowed us to evaluate intra-class correlation.

\section{Conclusion}

The results of this study indicate that low QoL was common among our sample of asthma patients. Efforts are needed to improve the QoL of patients with asthma in parallel with precise management plans. The increase in the incidence of this chronic disease in recent decades makes this a priority.

Funding: None.

Competing interests: None declared. 


\section{References}

1. The Global Asthma Report 2014. Auckland: Global Asthma Network, 2014 (http://www.globalasthmareport.org/resources/ Global_Asthma_Report_2014.pdf, accessed 20 March 2017).

2. Braman SS. The global burden of asthma.Chest. 2006 Jul 1;130(1_suppl):4S-12S.

3. To T, Stanojevic S, Moores G, Gershon AS, Bateman ED, Cruz $\mathrm{AA}$, et al. Global asthma prevalence in adults: findings from the cross-sectional world health survey. BMC Public Health. 2012 Mar 19;12(1):1.

4. Song WJ, Kang MG, Chang YS, Cho SH. Epidemiology of adult asthma in Asia: toward a better understanding. Asia Pac Allergy. 2014 Apr 1;4(2):75-85.

5. Varmaghani M, Rashidian A, Kebriaeezadeh A, Moradi-Lakeh M, Moin M, Ghasemian A, et al. National and sub-national prevalence, trend, and burden of asthma in Iran from 1990 to 2013; the study protocol. Arch Iran Med. 2014 Dec;17(12):804-9.

6. Heidarnia MA, Entezari A, Moein M, Mehrabi Y, Pourpak Z. [Prevalence of asthma symptom in Iran: a meta-analysis]. Pejouhesh. 2007 Oct 1;31(3):217-25 [in Farsi].

7. Reddel HK, Taylor DR, Bateman ED, Boulet LP, Boushey HA, Busse WW, et al. An official American Thoracic Society/European Respiratory Society statement: asthma control and exacerbations: standardizing endpoints for clinical asthma trials and clinical practice. Am J RespirCrit Care Med. 2009 Jul 1;180(1):59-99.

8. Wilson SR, Rand CS, Cabana MD, Foggs MB, Halterman JS, Olson L, et al. Asthma outcomes: quality of life. J Allergy Clinlmmunol. 2012 Mar 31;129(3):S88-123.

9. Felce D, Perry J. Quality of life: Its definition and measurement. Res DevDisabil. 1995 Feb 28;16(1):51-74.

10. Huss K, Naumann PL, Mason PJ, Nanda JP, Huss RW, Smith CM, et al. Asthma severity, atopic status, allergen exposure, and quality of life in elderly persons. Ann Allergy Asthma Immunol. 2001 May 31;86(5):524-30.

11. Voll-Aanerud M, Eagan TM, Plana E, Omenaas ER, Bakke PS, Svanes C, et al. Respiratory symptoms in adults are related to impaired quality of life, regardless of asthma and COPD: results from the European community respiratory health survey. Health Qual Life Outcomes. 2010 Sep 27;8(1):1.

12. Ried LD, Nau DP, Grainger-Rousseau TJ. Evaluation of patient's health-related quality of life using a modified and shortened version of the living with asthma questionnaire $(\mathrm{ms}-\mathrm{LWAQ})$ and the medical outcomes study, short-form 36 (SF-36). Qual Life Res. 1999 Sep 1;8(6):491-9.

13. Juniper EF, Norman GR, Cox FM, Roberts JN. Comparison of the standard gamble, rating scale, AQLQ and SF-36 for measuring quality of life in asthma.EurRespir J. 2001 Jul 1;18(1):38-44.

14. Doz M, Chouaid C, Com-Ruelle L, Calvo E, Brosa M, Robert J, et al. The association between asthma control, health care costs, and quality of life in France and Spain. BMC Pulm Med. 2013 Mar 22;13:15.

15. Montazeri A, Goshtasebi A, Vahdaninia M, Gandek B. The Short Form Health Survey (SF-36): translation and validation study of the Iranian version. Qual Life Res. 2005 Apr 1;14(3):875-82.

16. Stewart AL. Measuring functioning and well-being: the medical outcomes study approach. Durham (NC): Duke University Press; 1992

17. Ware JE, Snow KK, Kosinski M, Gandek B. New England Medical Center Hospital. Health Institute. SF-36 health survey: Manual and interpretation guide. Boston (MA): The Health Institute, New England Medical Center; 1993.

18. McHorney CA, Ware JE Jr, Lu JR, Sherbourne CD. The MOS 36-item Short-Form Health Survey (SF-36): III. Tests of data qual- ity, scaling assumptions, and reliability across diverse patient groups.Med Care. 1994;32(1):40-66.

19. Bousquet J, Knani J, Dhivert H, Richard AL, Chicoye AN, Ware JE Jr, et al. Quality of life in asthma. I. Internal consistency and validity of the SF-36 questionnaire. Am J RespirCrit Care Med. 1994 Feb;149(2):371-5.

20. Tavoli Z, Tavoli A, Amirpour R, Hosseini R, Montazeri A. Quality of life in women who were exposed to domestic violence during pregnancy. BMC Pregnancy Childbirth. 2016 Jan 26;16:19.

21. Delara M, Ghofranipour F, Azadfallah P, Tavafian SS, Kazemnejad A, Montazeri A. Health related quality of life among adolescents with premenstrual disorders: a cross sectional study. Health Qual Life Outcomes. 2012 Jan 1;10(1):1.

22. Darvish poor Kakhki A, Abed Saeedi Z. Health-related quality of life of diabetic patients in Tehran. Int J Endocrinol Metab. 2013;11(4):e7945

23. Haghpanah S, Nasirabadi S, Ghaffarpasand F, Karami R, Mahmoodi M, Parand S, et al. Quality of life among Iranian patients with beta-thalassemia major using the SF-36 questionnaire. Sao Paulo Med J. 2013;131(3):166-72.

24. Atabakhsh M, Mazaheri M. Responsiveness of the SF-36 questionnaire to the treatment outcome: a comparison of the mental and the physical patients. Modern Applied Science. $2016 \mathrm{Apr}$ 10;10(6):183-7.

25. Wong KO, Hunter Rowe B, Douwes J, Senthilselvan A. Asthma and wheezing are associated with depression and anxiety in adults: an analysis from 54 countries. Pulm Med. 2013 Mar 17;2013.

26. Sundberg R, Palmqvist $M$, Tunsäter $A$, Torén $K$. Health-related quality of life in young adults with asthma. Respir Med. 2009 Oct 31;103(10):1580-5.

27. Schatz M, Mosen D, Apter AJ, Zeiger RS, Vollmer WM, Stibolt $\mathrm{TB}$, et al. Relationships among quality of life, severity, and control measures in asthma: an evaluation using factor analysis. J Allergy Clinlmmunol. 2005 May 31;115(5):1049-55.

28. Oraka E, King ME, Callahan DB. Asthma and serious psychological distress: prevalence and risk factors among US adults, 20012007. Chest. 2010;137(3):609-16.

29. Jie $Y$, Isa ZM, Jie X, Ju ZL, Ismail NH. Urban vs. rural factors that affect adult asthma. Rev Environ ContamToxicol. 2013;226:33-63.

30. Moreira P, Moreira A, Padrão P, Delgado L. The role of economic and educational factors in asthma: evidence from the Portuguese Health Survey. Public Health. 2008 Apr 30;122(4):434-9.

31. Curtis LM, Wolf MS, Weiss KB, Grammer LC. The impact of health literacy and socioeconomic status on asthma disparities.J Asthma. 2012 Mar 1;49(2):178-83.

32. Pappa E, Kontodimopoulos N, Papadopoulos AA, Niakas D. Assessing the socioeconomic and demographic impact on health-related quality of life: Evidence from Greece. Int J Public Health. 2009;54:241-9.

33. Rajanandh $M G$, Nageswari $A D$, Ilango K. Influence of demographic status on pulmonary function, quality of life, and symptom scores in patients with mild to moderate persistent asthma. J ExpClin Med. 2014 Jun 30;6(3):102-4.

34. Wheaton AG, Ford ES, Thompson WW, Greenlund KJ, PresleyCantrell LR, Croft JB. Pulmonary function, chronic respiratory symptoms, and health-related quality of life among adults in the United States-National Health and Nutrition Examination Survey 2007-2010.BMC Public Health. 2013 Sep 17;13:854.

35. Lavoie KL, Bacon SL, Barone S, Cartier A, Ditto B, Labrecque M. What is worse for asthma control and quality of life: Depressive disorders, anxiety disorders, or both? Chest. 2006;130:1039-47. 